Ethiopian Journal of Environmental Studies \& Management 10(2): 192 - 207, 2017.

ISSN:1998-0507

Submitted: November 06, 2016

doi: http://dx.doi.org/10.4314/ejesm.v10i2.6

Accepted: March 10, 2017

\title{
ANALYSIS OF IMAGE DIFFERENCES OF ROADSIDE CORRIDOR AND LANDSCAPE PREFERENCE IN AN EMERGING CITY IN NIGERIA
}

\author{
ALABI, M.0. ${ }^{1}$ AND *ORIOLA, E.0. ${ }^{2}$ \\ Department of Urban and Regional Planning, Federal University of Technology, Akure, \\ Ondo State, Nigeria \\ Department of Geography and Environmental Management, University of Ilorin, P.M.B. \\ 1515, Ilorin, Kwara State, Nigeria
}

\begin{abstract}
This study examined the barrenness and clustered commercial activities along the ruralurban fringe of an emerging city (Lokoja, Nigeria) and tried to establish the inhabitant's preferred development pattern for road corridors at the fringe of the city. Questionnaire and photographs were utilized as research instruments for this study. Two roads: AbujaLokoja road (Nataco area) and the Lokoja-Kabba road towards the Kabba junction area were purposively selected for the study, and 204 copies of a questionnaire were randomly administered and 184 duly completed copies analyzed. Photographs were used as a surrogate to assess people's perception of the environment. Thirty (30) photographs taken within $10 \mathrm{~km}$ stretch were used. Six of the photographs served as "base" images and the remaining 24 as composite images of computer simulation and pictures adapted from similar research as an ideal situation. Five points Likert scale was used to measure respondent's preference. Principal component analysis (PCA) was employed to analyse the participants' responses to the questionnaire. The results revealed a high preference for an improved design with nature incorporated in developing commercial strip along the highway and low preference for existing billboard and haphazard development of the base images presented. It also revealed that design of roadways and commercial strip developments at the fringe could also have health implications. The paper suggests that trees and nature plants, in particular, should be used to improve visual quality and reduce Co2 in the Atmosphere through carbon sequestration.
\end{abstract}

Key Words: Rural-urban fringe; Landscape preferences; Commercial development; Road corridors; Highway design

\section{Introduction}

The pressure and congestion at the city center had led to the outward development of cities towards the fringes, where businesses have the cause to move to the city fringes to form linear shopping and filling stations arranged parallel to

*Corresponding Author: Oriola, E.O.

Email: lolaoriola@gmail.com major highways that connect the city with other towns. Many reasons have been put forward as pull factors to the fringes. Davies and Baxter (1997) attribute the factor to the tendency for businesses to enjoy patronage from high-density traffic along the highway, and high access to 
stores by the automobile operators, as they travel longer distances. Also, greater land availability for development and lower taxes, rent, plenty of spaces for parking and land values have been found to attract business to the fringes (James and Jaluzot, 2012).

Many businesses and shopping malls have moved from the city center to take advantages of the arterial roads as bypassing the city to form linear shopping developments arranged parallel to the highway which connects the city to its neighbouring towns. These have been termed by Davies and Baxter (1977) as commercial strips of linear commercial complexes.

The fringe areas of Nigerian cities have mostly been neglected or not in the phase of urban development. If it were, it is usually in the last phase of development of master plans. Despite the fact that most city master plans have plans with arterial roads passing through as bye passes. This bye passes with time often do not wait for the pace of development on the master plans which concentrate mostly on the developments of the city center. Hence development at the fringes is spurred by the presence of filling stations, block industries and mechanic workshops which serve as the harbinger of development (Alabi, 2015).

The intense rate of development and the aftermath of road construction had the consequences of loss of natural features such as ornamental plants which have affected visual appeal and the aesthetic quality of the landscape. Natural features such as trees, flora and fauna have been destroyed along the roadway corridors of express roads. This road presents visually chaotic scenario consisting of commercial developments that represent the bad side of urban sprawl, in a barren, monotonous and ugly situation. In most of such area also are junk yards and waste dumps. This is similar to the observation of Sullivan et al. (2006).

At this point, two questions suffix:

1. Are there agricultural and development patterns that local people prefer for the roadway corridors bridging the city and countryside?

2. What role does nature (trees, flowers, and grasses) play in people's preferences for the roadside settings in the rural-urban fringe?

The rural-urban fringe can be described as the landscape interface between town and country or a transition zone where urban and rural uses mix. Briant (1995) described the rural-urban fringe as an arena in which a variety of forces and processes operate to influence the structure and dynamic of human activities. This area has been found to be characterized by an assortment of land use types in the form of farmsteads, scattered developments and commercial strips tapered along arterial roads which in most cases are city bye passes. Friedberger (2000) found that the ruralurban fringe has become a target for rapid commercial development by a range of businesses such as car dealership, fast food restaurants, and super stores.

This paper, therefore, examines the extent to which commercial development along the road strip impacts the visual quality of the city fringes and the preference of city residents to the landscape development along the road corridor.

\section{Study Area}

Lokoja is located at the confluence of the Niger and Benue rivers. It lies between latitudes $7^{\circ} 45^{\prime}$ and $7^{\circ} 51^{\prime}$ North 
of the Equator and between longitudes $6^{\circ}$ $41^{\prime}$ and $6^{\circ} 45^{\prime}$ East of the Greenwich Meridian (Figure 1). It is well connected and accessible through state and federal highways. The town is sandwiched between a water body and a hill i.e. River Niger and Mount Patti respectively which had streamlined the settlement to a linear one and had a modifying effect on the climate. It is the gateway and transit point between the Northern, Eastern and
Southern parts of Nigeria. Lokoja is the Capital city of Kogi State, and also a Local Government headquarters. It has a land area of $3,180 \mathrm{~km} 2$ and a population of 195,261 (2006 census). It is bounded by Kabba bunu Local Government in the west, Koton karfe in the north, Ajaokuta Local Government in the east, Bassa Local Government in the southeast and Adavi Local Government in the south.

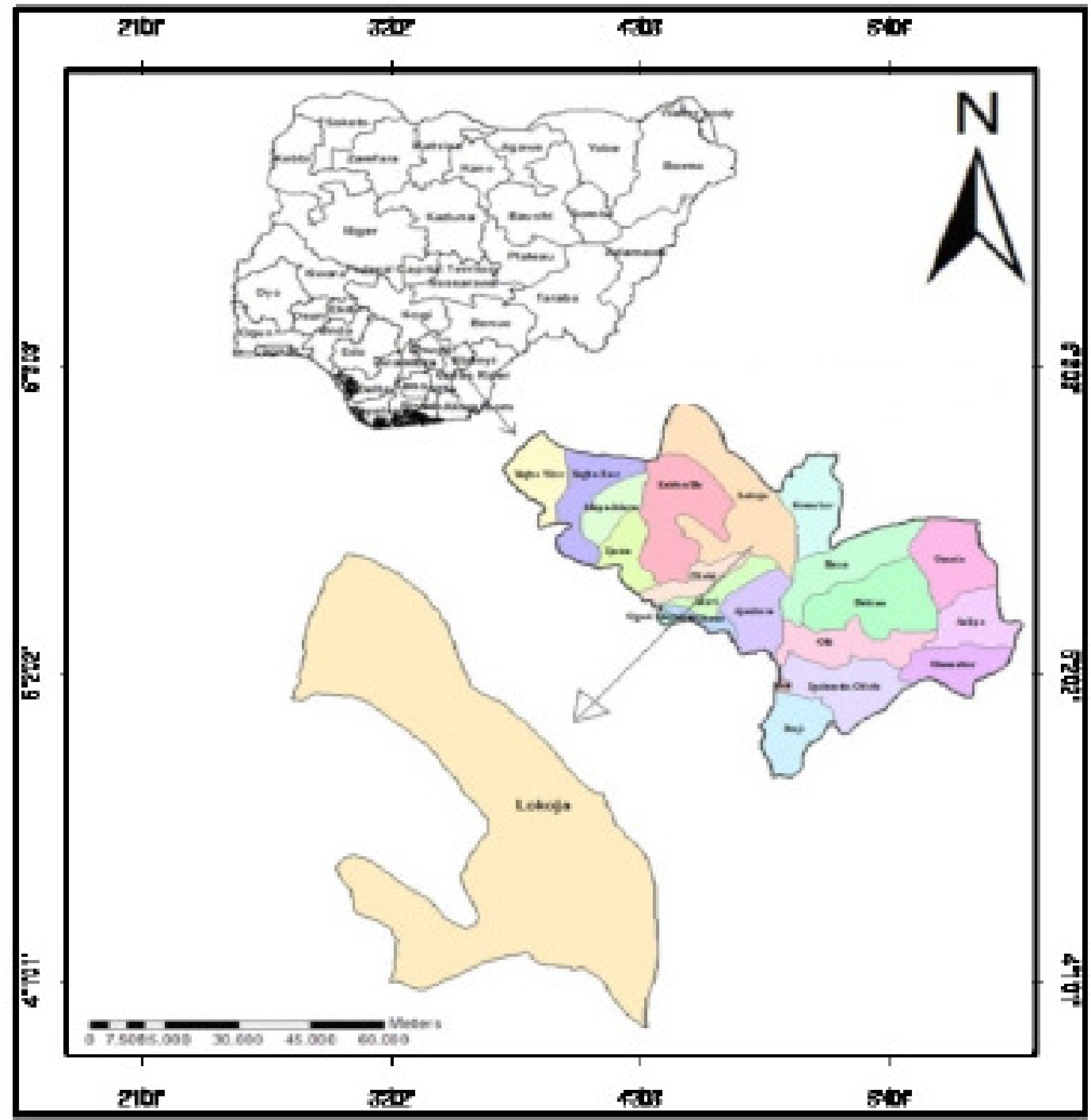

Figure1: The Study Area

Source: Oluwagbemi (2016) 
Analysis of Image Differences of Roadside Corridor.................ALABI \& ORIOLA

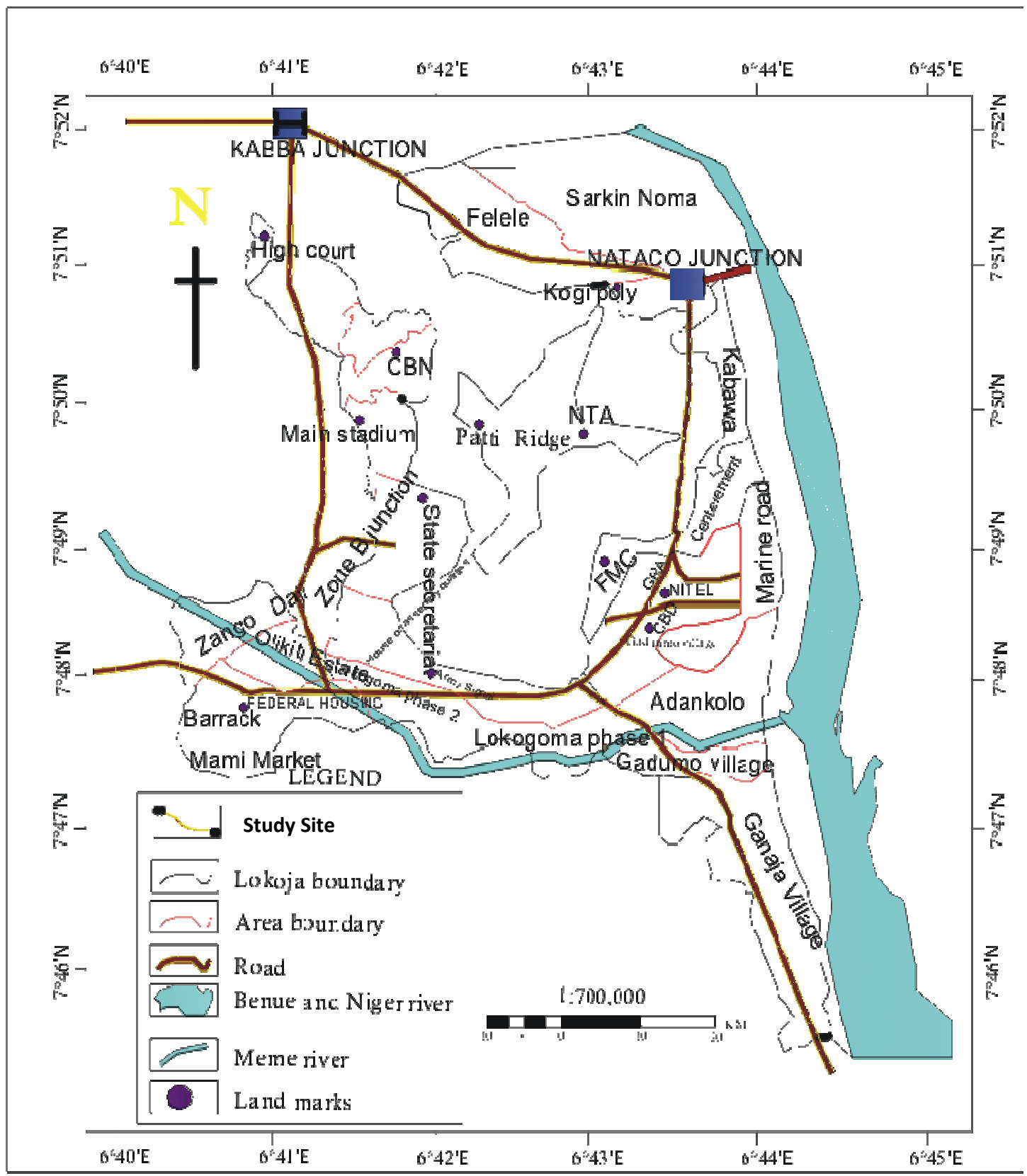

Figure 2: The Study Sites

Source: Alabi (2012)

The study was carried out on the Abuja-Lokoja-Okene highway which forms a link between these cities; precisely Natako junction to Kabba junction (Figure, 2). This area is characterized by the presence of a local business, restaurants, filling stations, mechanic junk yards which form disharmonious and incongruous developments on the landscape. These developments have led to poor visual quality of the route corridor.

\section{Materials and Methods}

In this research questionnaire and photographs were utilized as research 
instruments. Photographs were used as a surrogate to assess people's responses to their perception of the environment. This is because photographs provide control over environmental stimuli and make an affordable, extensive sampling of environments and individuals. Similarly, studies addressing the validity of photographs as environmental surrogates include Nassaur (1992), Zube et al. (1982), Brown, (1994), Hunziker and Kienast (1999) among others.

\section{Individual Units Analysis}

This study differs from most other inquiries into the validity of photo-based scenic beauty judgment in that; it compares individuals rather than group averages. It is suggested that the individual is the proper experimental unit of analysis for such inquiries. However, this is not to say that scenic beauty assessment of a group of persons cannot be represented by a measure of inappropriate for management or policy concerns. Rather it suggests that the comparisons of group measures are inappropriate for tests of validity when individuals and not groups are the experimental units responding to landscape stimuli (Hull and Stewart, 2014).

Hamond et al. (1980) described two contrasting approaches for aggregating human judgment as "ideographic and nomothetic." The nomothetic approach typifies photo based validity tests that compare group averages; experimental units are assumed to be replicates from the same population and therefore assumed to respond similarly to the "treatment" i.e. the landscape. Any difference among experimental units in their response is assumed to be random and unrelated to the factor being studied. Thus to compare group averages in a test of validity of photo-based assessment requires the assumption that the impact of contextual factors of landscape scenic beauty judgments are the same for each person, that each person will respond similarly to these factors and that any difference among person that do not exist are random and unrelated to the enquiry.

In contrast, the "ideographic" approach analyses each individual's data separately and aggregates individuals into groups when sufficient similarities exist. This concern is also reflected in the work of Robinson (1950) who makes the distinction between individual and ecological correlations. Individual correlations are correlations among attributes of indivisible experimental units, for example in the case of landscape scenic beauty assessment; the experimental unit is the person making the landscape assessment. The individual correlation of interest in test validity is the correlation between a person's photo based scenic beauty ratings while ecological correlations are correlation among survey measures.

\section{Study Area Analysis}

A photo-questionnaire was used to develop the preferences for various land use options for the selected route. The photo questionnaire included 30 photographs taken within a ten-kilometre stretch. The questionnaire focused on the relationship between the routes as it existed (a two lane road) and as it may exist in the future, based on surrounding land use and developments pattern.

Yamane (1967) formula was used to determine the sample size, and 204 copies of the questionnaire were administered. The 204 copies of the questionnaire were distributed within the two study sites, they are; the AbujaLokoja road (the Nataco area) and the 
Lokoja-Kabba road towards the Kabba junction area. Out of the 204 copies of a questionnaire distributed, $184(90 \%)$ duly filled and returned were used for final analysis. Six of the thirty photographs in the questionnaire served as "base" images. The base images showed open green nature area route that may be lost or dramatically altered as a result of development. Such scene was depicted by Sullivan and Lovell (2005) as "before" scenes.

The remaining twenty-four photographs were composite images, developed by computer simulation and pictures adapted from similar research as an ideal situation. The composite images communicated how the corridor might look under eight different conditions.

To assess preference for typical strip development along the route, the base images were modified to include commercial strip development; these images included considerably more trees planted in close association with buildings, parking lots and agricultural lands than is the norm for the route corridor. Two to six images were presented for each of the eight different conditions. Eight different conditions for the corridor fit into three classes that relate to the research questions about roadside settings at the rural-urban fringe. These classes are, "the typical development" and "development with trees" which attempts to answer the question regarding preferences for specific development patterns for roadway corridors. The third category compares preferences for commercially developed areas with or without trees focusing on the patterns that might accommodate economic development while enhancing the visual quality the corridor. Natural additions class specifically addresses questions about the role that nature plays in people's preferences for roadside settings. The conditions and number of images representing each of these three categories are identified in table 1.

Participants were made to indicate their preferences of the 30 pictures by selecting a number on a five-point Likert scale located beneath each photograph. A "1" on the scale denoted very low preference, while " 5 " denoted very high preference.

The attitude of the people was investigated about design and development by making them respond to the visuals on the pictures. The people were also asked to answer the questionsthat deal with visual quality.

In this study, research participants responded to 17 items concerning the development and visual quality of the highway. Also a five-point Likert scale, with a rating of " 1 " indicating a low or negative assessment, while " 5 " indicated the highest or most positive assessment. The responses to questionnaire items were examined using principal component analysis (PCA) to group the items into related categories. This method was adapted from Sullivan and Lovell (2005). 
Table 1 Modification to the base images on the highway

\begin{tabular}{ll}
\hline Mode of development & $\begin{array}{l}\text { Number of images } \\
\text { in photo-questionnaire }\end{array}$ \\
\hline $\begin{array}{l}\text { Existing situation } \\
\text { Billboards, haphazard development with unorganized commercial strip }\end{array}$ & 4 \\
Commercial strip development, without parking space, haphazard & 4 \\
parking on roadsides & 3 \\
Development strip : & 3 \\
with large parking lot, without landscaping & 3 \\
with small parking lot without landscaping & \\
Development with trees naturally around commercial strip & \\
development & 3 \\
Alternative situation & 2 \\
Alternative road corridor design, organized parking space with: & 2 \\
Flowers and grasses & 3 \\
Trees in row with well-placed billboards & 3 \\
Landscaped roadside and center & 3 \\
Development with large parking lot, adoption of natural vegetation & 3 \\
Development with small parking lot, with Trees in row &
\end{tabular}

Source: Adapted from Sullivan and Lovell (2005)

\section{Results}

The participant's ratings of the existing conditions along the highway were examined and compared with a variety of development scenarios. The picture ratings were presented after which reactions to the items on the questionnaire collated.

\section{Base images}

Physical Development: Plate 1 shows two images from the billboard and haphazard development category with spaces at different distance from the sides of the road. It also shows small-scale commercial developments on both sides of the road. This category obtained a mean rating of 1.5 , with a range of 1.5 to 2.1 . This category was found to have attained the lowest preference rating in all the categories under study. 


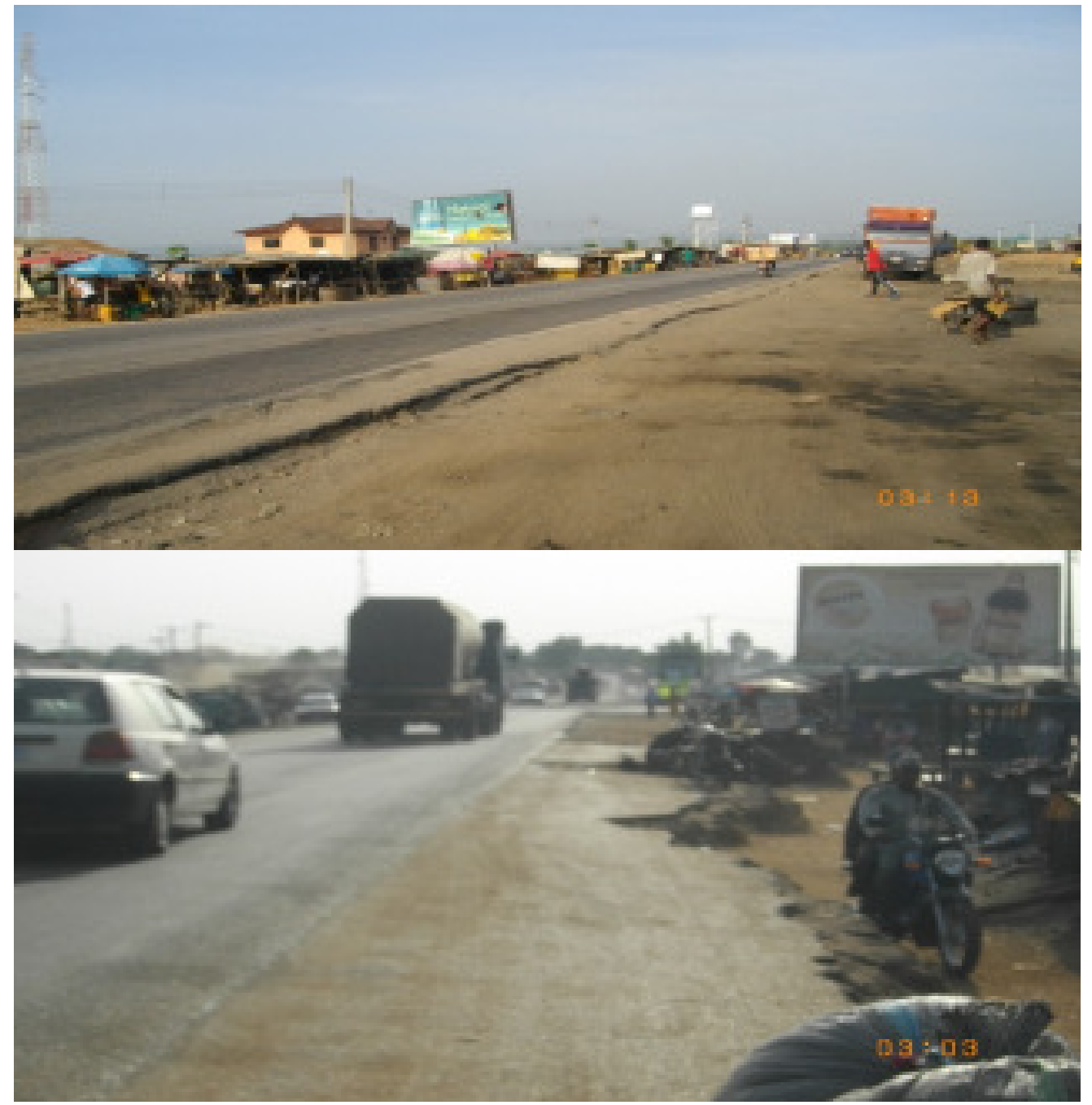

Plate 1: Images on billboards and haphazard development category (mean1.5)

\section{Economic Development}

Plate 2 presents pictures from commercial development category with small unorganized commercial activities on the sides of the highway; this also recorded a very low rating of 1.6 with a range of 1.5-1.9, this also earned a very low preference as compared to other categories. 


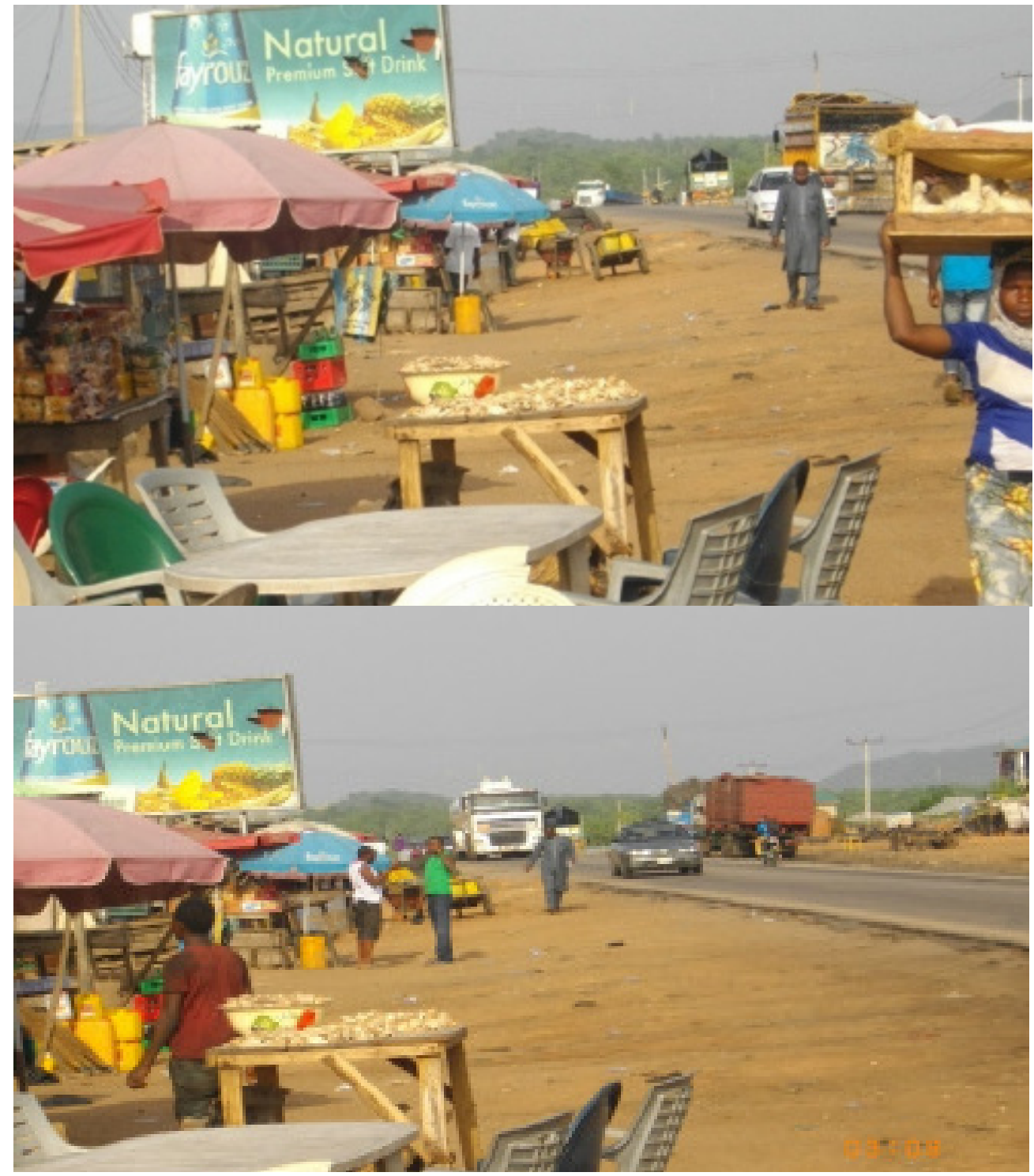

Plate 2: Commercial development stripwith unorganized setting at road corridor category, mean ( 1.6).

\section{Development Strip at Road Corridor}

Plate 3 category of development strip on road corridor with unorganized parking of vehicles on the roadside is presented. The mean for this category was found to be 1.82 with a range of 1.8-
2.0. It depicts that one side of the road is already being degraded as a result of erosion due to exposure to the soil. This again compared to the other categories also reflects low preference ratings. 


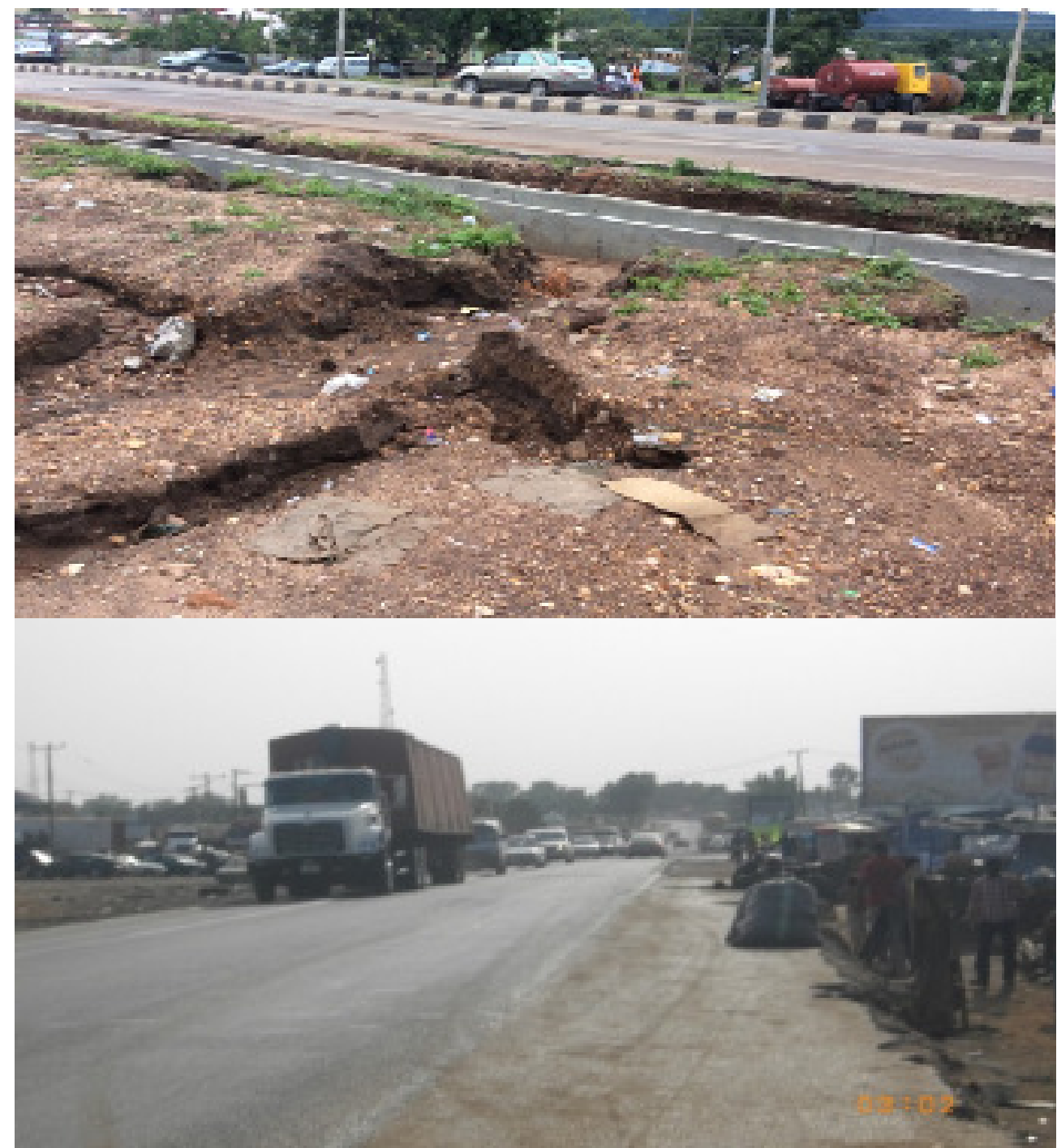

Plate 3: Road corridor with erosion due to loss of vegetation and on another side with unorganized parking space on roadside category, (mean 1.82).

\section{Commercial Development with Trees}

Plate 4 shows area with development; the area is with trees naturally still around the commercial strips, with vegetation still preserved due to sparse development, vegetation on the roadside is untrimmed, road center non-functional, with trees and grasses growing untrimmed. the participants in the survey rated this images as development with natural vegetation high with a mean of 3.5 indicating a strong preference

\section{Alternative Road Corridor Design}

The Plate 5 shows alternative road corridor design category with welldefined parking spaces at the roadsides; road edges are landscaped. Also, the road center is made functional with grasses and billboards are of optimum size. It has a mean of 4.4 which indicates very high preference. 


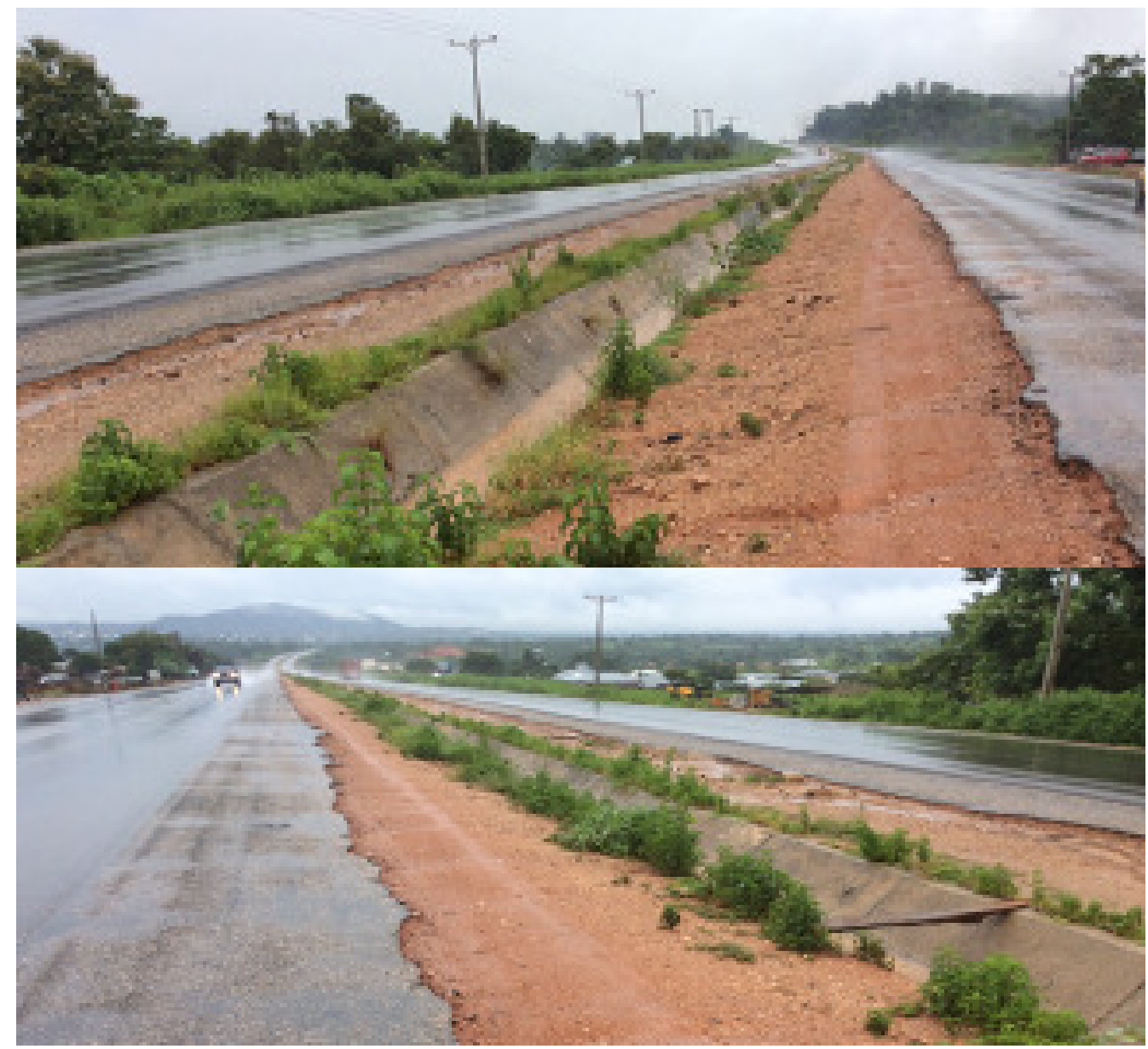

Plate 4: Two roadside images with natural and vegetation untrimmed category(mean 3.2)

\section{Natural Additions}

This is the last of the mode of the images, this depicts the roadsides planted with trees, added along the edges of the highway, this also serves as an alternative to the existing situation (plate 6).
Participants rated the categories in this class significantly higher than the base images, with a mean range of 3.5 to 4.5 , which is indicative of a very high preference. 


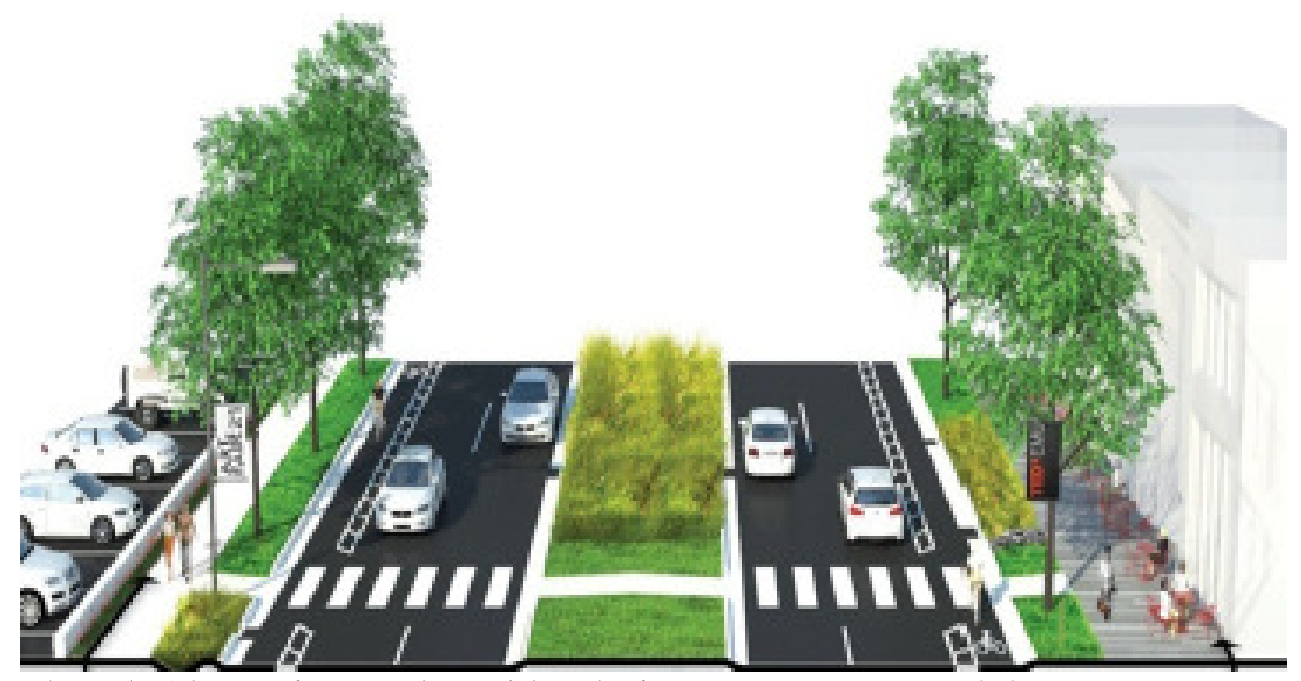

Plate 5: Alternative road corridor design category, mean 4.4. (Adapted from Washtenaw Charette design workshop)
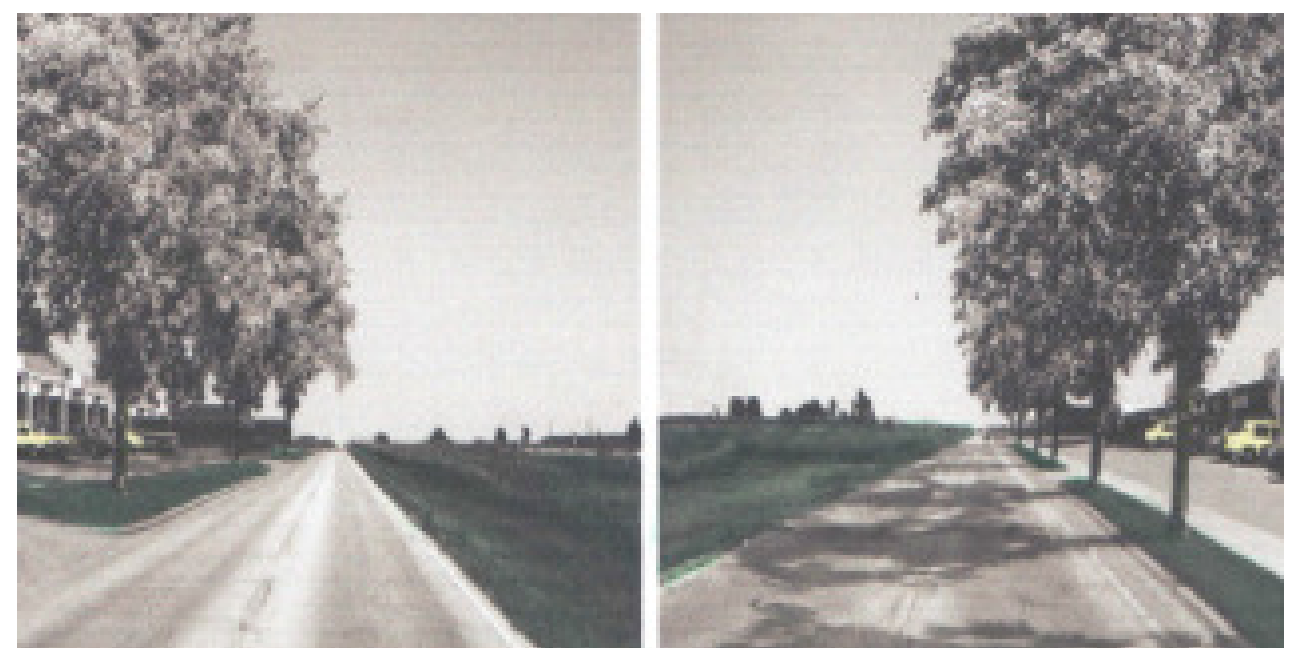

Plate 6: Two images showing most preferred commercial strip planted with trees, with the natural vegetation well-trimmed category, mean 3.3

(Adapted from Sullivan and Lovell (2005).

\section{Principal Component Analysis (PCA)}

Table 2 presents the PCA analysis of the responses from the copies of aquestionnaire administered. The PCA grouped the 17 responses to a set of six categories. Each category included items that had a strong relationship with one another. The six categories are I: typical development with billboards, II:economic developments, III: development strip at road corridor IV: Commercial
Development with trees V: Alternative road corridor design and VI: natural additions. This result was found to be consistent with the picture preferences, where the typical development (billboard) category earned the lowest mean of 2.0, which is indicative of the people's negative attitudes about billboard arrangement on the roads. This could be corroborated with theresult of the preference data. The economic 
development, the second category also showed a negative preference with a mean of 2.25 which is also of lower preference, also consistent with that of the picture preference. The third category, development with a strip of trees along the road corridor, however, indicated high preferences, strong support for tree planting, organized parking space along the highway with a mean of 5.95. This outcome is also in tandem with preference data that trees should be planted along the highway routes, and the center of the roads should be made functional. This is to increase the visual quality of the road. The fourth category is the development with trees, these includes commercial development with strip development of trees, development with large parking lot and development with a small parking lot, with a mean of 6.9, Again, this high preference level is also in agreement with that of the picture preference level. The fifth category is the alternative road design corridor with a mean of 8.9 which indicates high preference. This is a description of computer simulated image of a well-landscaped road corridor with roadside paved (see plate 5). The sixth category is the natural additions, with trees grass planted and well trimmed.

Table 2: Means ratingand categories of written questionnaire items

\begin{tabular}{|c|c|c|c|}
\hline Category & Mean rating & Std. deviation & Analysis N \\
\hline $\begin{array}{l}\text { Class I: Typical Development } \\
\text { Adding more billhoards }\end{array}$ & 2.0000 & .79372 & 20 \\
\hline \multicolumn{4}{|l|}{ Adding more billboards } \\
\hline Class 11: Economic Development & 2.2500 & .91047 & 20 \\
\hline \multicolumn{4}{|l|}{ Encouraging development of the fringe areas } \\
\hline \multicolumn{4}{|l|}{ Encouraging new commercial development } \\
\hline \multicolumn{4}{|l|}{ Encouraging new residential development } \\
\hline & 5.9500 & 2.56443 & 20 \\
\hline \multicolumn{4}{|l|}{ Class III: Development Strip at Road Corridor } \\
\hline $\begin{array}{l}\text { Class IV: Commercial Development with Trees } \\
\text { Planting more trees along the highway }\end{array}$ & 6.9300 & 2.15455 & 20 \\
\hline Class V: Alternative Road Corridor Design & 8.9000 & 4.61006 & 20 \\
\hline \multicolumn{4}{|l|}{ Planting trees in rows } \\
\hline \multicolumn{4}{|l|}{ Improving visual quality } \\
\hline \multicolumn{4}{|l|}{ Improving visual attractiveness } \\
\hline \multicolumn{4}{|l|}{$\begin{array}{l}\text { Encourage commercial development with landscape } \\
\text { guideline }\end{array}$} \\
\hline Class VI: Natural Additions & 9.1000 & 4.07689 & 20 \\
\hline \multicolumn{4}{|l|}{ Preserving rural character } \\
\hline \multirow{2}{*}{\multicolumn{4}{|c|}{ Preserving agricultural land at the fringes }} \\
\hline Maintaining green, open space between cities & & & \\
\hline INFO & 31.7000 & 7.26998 & 20 \\
\hline
\end{tabular}

\section{Discussion}

This present study explored systematic differences in images of the roadside corridor and landscape preferences among the inhabitants of Lokoja including commercial vehicle drivers plying the road regularly. The result revealed a very low preference for existing billboard and haphazard development category of base images presented. It also shows low preferences for the image with the scenario of 
commercial strip development without organized parking space. However, the presentation of alternative images elicited responses which depict commercial strip development with the addition of trees which was seen to improve thevisual quality of the commercial setting. The addition of trees with some form of landscaping was found to be very high preference. This result was corroborated by the findings from the questionnaire response, which also indicated a strong preference for thea ddition of trees, organized parking and landscaping of the commercial strip on the fringe of the highway. These is indicative of low preference to placements of large billboards. The findings provide information and source of data about the people's preference for the nature of road side settings; it also suggests design alternatives for land use at the ruralurban fringe. Planners and citizens should insist upon a healthy tree canopy for all new development at the ruralurban fringe.

The study is emphasizing that in environmental management and road design, planners should not lose sight of the aspect of green infrastructure when planning and designing roads within the city fringes. As a matter of policy, planners should take advantage of the low cost involve in incorporating nature at the road side of the fringe highways in the early stages of the planning process, because the cost of improving the quality and quantity would be higher when changes are made after development are already in place, especially when vegetation is allowed to grow naturally. The findings are in line with Myers (2002), that low-cost approaches to tree planting or natural vegetation have the tendency of improving the view and that allowing vegetation to grow naturally on the roadways could decrease maintenance cost.The study also suggests that commercial development can be combined with natural features with an outcome of an excellent visual appeal and high functionality. It also demonstrates that the peoples' preferences should be considered in the design of roads in the urban fringe, which is consistent with public evaluation of many landscape settings by Kaplan (1983) and Schroeder (1989).

The study also has health implications due to the health benefits of human exposure to nature. A study by Frumkin (2001) have shown that settings that contain nature or environment with trees and grasses can encourage recovery from mental fatigues and restore mental functioning. Exposure to nature has also been found to enhance the ability to cope with and recover from physiological stress (Ulrich, 1984) Frumkin (2001). It could also be of help to travelers who will be in the vehicle for a longer period of time. It is also known to have an impact on their ability to function optimally particularly while driving.

The carbon sequestration of green chlorophyll of the plant can not be overemphasized more importantly in this era of global warming. In fact, trees make places look and feel better. As well as playing a role in climate proofing our neighborhoods and supporting human health and environmental well-being. The greener the city, the cleaner the atmosphere and the healthier the people.

\section{Conclusion}

This paper concludes that 'green construction' has a great benefit for urban environment, aside from the health benefit and erosion control, it also adds to 
the scenic beauty of cities. This is perhaps why people give preference to road corridors with improved design and nature incorporated in developing commercial strip along the highway. Hence the need for tree planting to improve visual quality and to reverse warming environment through reduced $\mathrm{CO}_{2}$ in the Atmosphere.

\section{References}

Alabi, M.O. (2012). The built up environment and micro- climate variation in Lokoja, Nigeria. American Journal of Contemporary Research, 2(12): 150-158.

Alabi, M.O. (2015). Determinants of factors of land use Dynamics in North Central Nigeria. Unpublished Ph.D. Thesis, Department of Urban and Regional Planning. University of Nigeria, Nsukka

Alabi, M.O. and Oriola, E.O. (2009). Prioritizing Factors of Failure in the Control of Physical Development in Nigeria. $A D S U$ Journal of Social Science \& Development Studies, 2(2): 112 121.

Briant, C.R. (1995). The role of local actors in transforming the urban fringe . Journal of Rural Studies, 11(3): 255-267.

Brown, T. (1994). Conceptualizing smoothness and density as landscape elements in visual resource management. Landsc Urban Plan, 30: 49-58.

Davies, W.K.D. and Baxter, T. (1997). Commercial intensification: the transformation of a highwayoriented ribbon. Geoforum, 28(2): 237-252.
Friedberger, M. (2000). The rural-urban fringe in the late twentieth century. Agricultural History, 74(2):502-514.

Frumkin, H. (2001). Beyond toxicity: human health and the natural environment. American Journal of Preventive Medicine, 20(3): 234240.

James, S. andJaluzot, A. (2012). "Trees in the townscape: a guide for decision makers." Trees \& Design Action Group, UK. http://www.tdag.org.uk/trees-in-thetownscape.html

Kaplan, S. (1983). A model of personenvironment compatibility. Environment and Behavior, 15: 311332.

Hammond, K.R,. McClelland, G.H. and Mumpower, J. (1980). Human judgment and decision making :Theories , methods, and procedures. New York.

Hull, R.B. and Stewart, W.P. (1992). The validity of photo-based scenic beauty judgments. Journal of Environmental Psychology, 12: 101-114.

Hunziker, M. and Kienast, F. (1999). Potential impacts of changing agricultural activities on scenic beauty - a prototypical technique for automated rapid assessment. Landscape Ecology, 14(2):161-172.

Myers, M.E. (2002). One view from the road: where is the leading edge of highway aesthetics to be found? A critical review ofa recent road inventory in Michigan. Landscape Architect. 10:80-87.

Nassauer, J.I. (1992). Framing the landscape in photographic simulation. Journal of Environmental Management, 11:116. 
Oluwagbemi, E.O. (2016). Unpublished MGIS Dissertation, Department of Geography and Environmental Management, University of Iorin, Ilorin, Nigeria

Robinson, W.S. (1950). Ecological Correlation and the Behavior of Individuals. American Sociological Review, 15: 351-357.

Schroerder, H.W. (1989). Environment, behavior and design research on urban forest. In Zube, E.H. and G.T Moore (Eds). Advances in Environment, Behaviour and Design (Vol. 2) Plenum, New York, pp87-117.

Sullivan, W.C., Anderson, O.M. and Lovell, S.T. (2006). Buffers at the rural-urban fringe: a strategy approved by farmers, residents, and scientists. Landscape Urban Planing Journal, 69: 299-313.

Sullivan, W.C. and Lovell, S.T. (2005). Improving the visual quality of commercial development at the rural-urban fringe. Landscape Urban Planing Journal 77:152166.

Ulrich, R.S. (1984). View through a window may influence recoveryfrom surgery. Science 224 : 420-421.

Ulrich, R.S. (1983). Aesthetic and affective response to natural environment. In: I. Altman and J.F. Wohlwill (Eds.), Human behavior and environment: advances in theory and research.Vol. 6 (pp. 85125). New York: Plenum Press

Yamane, T. (1967). Statistics, An Introductory Analysis, 2nd Ed., New York: Harper and Row

Zube, E.H., Sell, J.L. andTailor, J.G. (1982). Landscape perception: Research application and theory. Landscape Panning, (1): 1-33. 